\title{
CONE)-(OES
}

CIÊNCIA E TECNOLOGIA

\section{UMA CONTRIBUIÇÃO PARA O DESENVOLVIMENTO DE VOCAÇÕES CIENTÍFICO-TECNOLÓGICAS: O LENQUI COMO ESPAÇO DE EDUCAÇÃO}

\author{
Andreza Cipriani, ARleide Rosa Da Silva \\ UNIVERSIDADE REGIONAL DE BLUMENAU - FURB \\ <andrezacipriani@hotmail.com>.<arosa@furb.br> \\ DOI: $10.21439 /$ conexoes.v15i0.2086
}

\begin{abstract}
Resumo. Investigações a respeito das atitudes dos estudantes frente à ciência e à tecnologia têm se popularizado e evidenciam diminuição do interesse desses em seguir carreiras científicas no Brasil. Desse modo o objetivo desta pesquisa exploratória é identificar os interesses dos jovens em relação às vocações científico-tecnológicas, a fim de estabelecer uma relação entre as suas experiências e as futuras profissões. Para diagnosticar os perfis dos estudantes foi realizada uma pesquisa qualitativa aplicando-se um questionário em meio físico com perguntas fechadas em um espaço não formal de aprendizagem denominado Laboratório de Ensino de Química (LENQUI) na Universidade Regional de Blumenau - FURB/SC. Participaram do estudo setenta e seis alunos de $1^{\circ}$ ao $3^{\circ}$ Ano do Ensino Médio oriundos de 23 escolas da rede pública e particular. Os dados gerados foram compilados em gráficos e segregados por gênero a fim de apresentar as características da amostra e as respostas obtidas foram analisadas a luz das vertentes científicas específicas associadas à aprendizagem dos alunos em ambientes informais. Os resultados obtidos apontam que a maioria dos estudantes possui interesse por temas científicos, destacando-se no item tecnologia. Em relação ao futuro, consideramos que estes apresentam atitudes preditoras positivas quanto às questões ambientais em comparação às questões humanas, e apesar de apresentarem interesses pela ciência, ambos os gêneros não demonstraram uma visão otimista em ingressar na carreira científica.
\end{abstract}

Palavras-chaves: Educação científica. Espaço não formal. Vocações científico-tecnológicas.

\section{A CONTRIBUTION FOR THE DEVELOPMENT OF SCIENTIFIC-TECHNOLOGICAL VOCATIONS: LENQUI AS A TEACHING TOOL}

\begin{abstract}
Investigations regarding students' attitudes towards science and technology has become popular and show a decrease in their interest in pursuing scientific careers in Brazil. Thus, the objective of this exploratory research is to identify the interests of young people in relation to scientific and technological vocations, aiming to establish a relationship between their experiences and future professions. In order to diagnose the student's profiles, a qualitative research was carried out by applying a questionnaire in a physical environment with closed questions in a non-formal learning space called Chemistry Teaching Laboratory (LENQUI) at the Regional University of Blumenau - FURB / SC. Seventy-six students from the 1st to the 3rd year of high school from 23 public and private schools participated in the study. The data generated were compiled into graphs and segregated by gender in order to present the characteristics of the sample and the responses obtained were analyzed in the light of specific scientific aspects associated with student learning in informal environments. The results obtained point out that the majority of students have an interest in scientific topics, especially in the item technology. In relation to the future, we consider that they have positive predictive attitudes towards environmental issues compared to human issues, and although they have interests in science, both genders have not shown an optimistic view of entering the scientific career.
\end{abstract}

Keywords: Scientific Education, non-formal learning space, Scientific and technological vocations. 


\section{INTRODUÇÃO}

A utilização de um laboratório de ensino de ciências pelos alunos da educação básica vem sendo relatada como um ambiente inspirador e facilitador da aprendizagem, tornando-se parte importante na compreensão das disciplinas envolvidas nesta área (SCHWAHN; OIAGEN, 2008). Por sua vez, este espaço de ensino não formal, propõe que experiências diretas de observação e manipulação de materiais científicos sejam superiores a outros métodos utilizados para desenvolver a compreensão e o gosto pela ciência, e com isso contribuem de maneira significativa para o fomento de vocações científico-tecnológicas (BARAM-TSABARI; YARDEN, 2005; TôZO, 2005, WOMER, 2014). Em seus estudos Santos-Gouw (2013), destaca que os jovens brasileiros têm uma atitude otimista em relação à ciência e tecnologia, e a considera não só responsável pela cura de doenças futuras, como por melhores oportunidades profissionais e o desenvolvimento adequado de um país. Resultados semelhantes foram apresentados pelo projeto The Relevance of Science Education (ROSE), que busca coletar dados de natureza atitudinal e emocional dos estudantes, abordando aspectos que podem ser importantes para o engajamento tanto na ciência escolar como na escolha das futuras profissões. Os autores argumentam que questões escolares relacionadas às atitudes desses alunos possuem um efeito mais duradouro, e são determinantes para a escolha de opções de futuro dos estudantes (SCHREINER; SJØBERG, 2004). Apesar de tantas razões que justifiquem a relevância do ensino de ciências por meio da experimentação durante a educação básica, a educação científica encontra-se diante de um desafio: ajustar-se ao mundo moderno, atendendo as necessidades de todos os alunos, querendo eles seguir carreira científica ou não. Investigações a respeito das atitudes dos estudantes frente às ciências têm aumentado de maneira significativa, e ao mesmo tempo demonstram que há evidencias da diminuição do interesse dos jovens em seguirem carreiras científicas, sendo alguns dos principais motivos à falta de promoção do interesse pelos professores, exposição à ciência de forma sistemática, organizada e explícita e ainda, a falta de aproximação dos conteúdos com a realidade escolar (FOUREZ, 2016; SEDANO; CARVALHO, 2017).

O aprendizado das ciências deve ser divertido e significativo para o aluno, de forma a favorecer as atitudes que os motivem na aquisição de conhecimentos com expressivas melhorias na sua aprendizagem. Diversos são os exemplos da importância e influência das ciências e da tecnologia na vida do ser humano, desde o modo como vivemos, agimos, pensamos até como soluciona- mos nossos problemas no cotidiano. Sendo assim, a Base Nacional Comum Curricular (BNCC) no que diz respeito às competências específicas e habilidades na área das Ciências da Natureza e suas Tecnologias, propõe um aprofundamento científico nas temáticas que envolvem a Química, Física e a Biologia, para o aprendizado não só de conteúdos conceituais previstos nos currículos escolares, mas de uma abertura para um olhar articulado que permite a ampliação e a sistematização das aprendizagens essenciais desenvolvidas em todo o ensino básico (BRASIL, 2018). Diante disso, entendese a importância dos conceitos e princípios de diversos campos científicos para os estudantes, que ao longo dos anos de formação na educação básica, vão construindo valores cada vez mais abrangentes. Estes valores vão sendo influenciados por novas experiências de investigação, aquisição de diferentes linguagens e relações entre ciência, a tecnologia e a sociedade e assim, aumentando o número de jovens estudantes que optam por formação em áreas que envolvem as vocações STEM (sigla em inglês para Ciência, Tecnologia, Engenharia e Matemática), principalmente aquelas que envolvem as Ciências (Química, Física e Biologia) (SASSERON, 2015, KAROLCZAK, 2017). Estudos apontam que, a atividade do aluno, a natureza sensório-motora da experiência e a individualização do ensino em um laboratório de experimentação científica contribuem positivamente para a aprendizagem (PINAFO, 2016, SANTOSGOUW, 2013).

Sendo assim, o LENQUI - Laboratório de Ensino de Química (figura 1) foi idealizado em 2017 como um novo espaço educativo vinculado ao curso de Química da Universidade Regional de Blumenau - FURB/SC destinado à formação de professores em Educação Científica e atendimento personalizado aos estudantes da educação básica tendo em vista a aproximação das escolas com a universidade, onde terão a oportunidade de produzir, implementar e analisar práticas educativas diferenciadas, além de dispor de materiais didáticos adequados aos assuntos abordados em suas instituições de origem. Neste espaço também são desenvolvidas ações extensionistas pois o mesmo integra o coletivo do Programa HABITAT - Educação Científica, Educação e Meio Ambiente que atua na promoção de práticas educativas inovadoras com foco em Educação Científica e Ambiental em um espaço híbrido, com arranjo de laboratórios da FURB (LIE, LIFE, LENQUI, LaBot, EfeX) para formação de estudantes e seus professores. Como resultados efetivos, no ano de 2019 foram agendadas 65 visitas e atendidas: 61 escolas diferentes ( 3 federais; 5 privadas; 22 estaduais e 31 municipais); 12 cidades de Santa Catarina envolvidas: Blumenau, Gaspar, Indaial, 
Timbó, Pomerode, Imbuia, Ascurra, José Boiteux, Guabiruba, Jaraguá do Sul, Florianópolis e Rio do Oeste; 2192 estudantes da Educação Básica participantes: 6 turmas de Educação Infantil; 36 de Ensino Fundamental e 23 de Ensino Médio, acompanhados de seus professores.

Figura 1: Atividades desenvolvidas pelo LENQUI, 1- Bolsistas e licenciandos que atuam no LENQUI 2 - Oficina Detetive por um dia: aprendendo a investigar por meio da Química Forense 3 - logotipo do LENQUI 4 - prática educativa para crianças do EF - anos iniciais 5 logotipo do curso de Química.

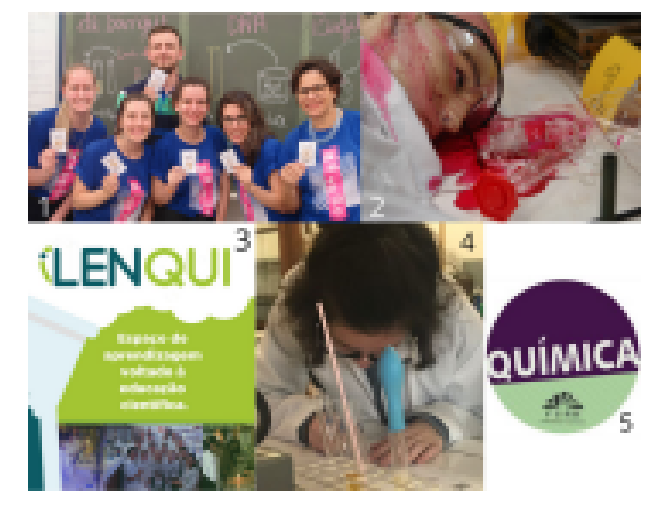

Assim, conhecer os interesses que os jovens da educação básica têm pela ciência e tecnologia é o principal objetivo desta pesquisa, que busca ainda, a partir deste diagnóstico compreender o perfil dos estudantes a respeito das vocações científico-tecnológicas. A partir da análise das escolhas nessas áreas, foi possível estabelecer uma relação entre as suas experiências e seus interesses dentro e fora da escola, e também na opção profissional destes jovens estudantes. Para diagnosticar o perfil das vocações científico-tecnológicas dos estudantes, foi aplicado um questionário com perguntas fechadas, em escala Likert de 4 pontos, utilizando como base para sua elaboração as questões norteadoras apontadas no projeto ROSE (SCHREINER; SJØBERG, 2004). A aplicação do questionário em meio físico e presencial teve início em julho de 2018, com alunos de diferentes faixas etárias, durante o atendimento do LENQUI às escolas de educação básica da região de Blumenau - SC, finalizando em maio de 2019.

\section{Vertentes Da Aprendizagem Científica: Es- paço De Aprendizagem Não Formal}

Em 2009, sob a coordenação do Conselho Nacional de Pesquisa (National Research Council) dos EUA, foi publicado um relatório bastante amplo, o qual se refere a trabalhos que estão relacionados à aprendizagem científica em ambientes informais. Neste, são articulados um conjunto de seis habilidades científicas específi- cas denominadas vertentes da aprendizagem da ciência (strands of science learning), estando elas apresentadas, na Tabela 1. As vertentes de aprendizagem são definidas pelo relatório como fios de uma corda (strands of a rope), para a "produção de experiências, ambientes e interações sociais", com foco em todas as idades no intuito de uma "maior compreensão, fluência e perícia científica" (NATIONAL RESEARCH COUNCIL, 2009).

Fenichel e Schweingruber (2010, p. 2-5), observam ainda que uma característica interessante das vertentes da aprendizagem da ciência em ambientes informais é que elas estão interligadas, de tal forma que o progresso em uma delas contribui para a continuidade das outras. $\mathrm{Na}$ literatura, são extensas as discussões a respeito das definições de aprendizagem em ambiente formal e informal. De maneira geral, o que diferencia a educação formal da informal é que a primeira "está presente no ensino escolar institucionalizado" BIANCONI; CARUSO, 2005, p. 20), enquanto a informal é aquela em que "qualquer pessoa adquire e acumula conhecimentos, através de experiência"(Bianconi; Caruso, 2005, p. 20). Há aquelas mais completas que apresentam o aprendizado em três categorias distintas: formal, informal e não formal (EUROPEAN COMMISSION, 2004 apud ARRUDA et al., 2013, p. 32-33). Os espaços de aprendizagem não formais ainda podem ser definidos de acordo com Jacobucci (2008) em duas categorias: a) institucionalizado, pois pertence a uma pessoa jurídica como instituição privada ou pública, como por exemplo, Museus, Centros de Ciências, Parques Ecológicos, Institutos de Pesquisa, etc e b) não institucionalizado, porque não pertence a qualquer organização (pessoa jurídica) que o tenha estruturado para tal finalidade, mas onde é possível adotar práticas educativas, como em teatros, parques, praças, dentre outros. Cabe ressaltar que no presente trabalho utilizamos a definição para aprendizagem em espaço não formal o qual oportuniza a aquisição "de conteúdos da escolarização formal em espaços como museus, centros de ciências, ou qualquer outro em que as atividades sejam desenvolvidas de forma bem direcionada, com um objetivo definido" (VIEIRA; BIANCONI; DIAS, 2005, p. 21), sendo possível contemplar nessa definição, o LENQUI, local de aplicação deste estudo.

As experiências de aprendizagem de ciência em ambientes não formais, podem ser caracterizadas como "motivadoras, guiadas pelos interesses do aluno, voluntárias, pessoais, continuadas, contextualmente relevantes, colaborativas, não lineares", e que levam à compreensão de que "aprender a ciência pode ser prazeroso, importante e gratificante"(NATIONAL RESE- 
Tabela 1: Vertentes da aprendizagem da ciência

\begin{tabular}{|c|c|}
\hline Vertentes & Definição \\
\hline $\mathbf{1}$ & $\begin{array}{r}\text { Experimentar a excitação (emoção), interesse e motivação para aprender } \\
\text { sobre os fenômenos no mundo natural e físico }\end{array}$ \\
$\mathbf{2}$ & $\begin{array}{r}\text { Gerar, entender, lembrar e usar conceitos, explicações, argumentos, } \\
\text { modelos e fatos relacionados à ciência; }\end{array}$ \\
$\mathbf{3}$ & $\begin{array}{r}\text { Manipular, testar, explorar, prever, questionar, observar e dar sentido } \\
\text { ao mundo natural e físico }\end{array}$ \\
$\mathbf{4}$ & $\begin{array}{r}\text { Refletir sobre a ciência como forma de conhecer; em processos, conceitos } \\
\text { e instâncias da ciência; e em seu próprio processo de aprender sobre fenômenos } \\
\text { Participar de atividades científicas e práticas de aprendizado com os } \\
\text { outros, usando linguagem científica e ferramentas }\end{array}$ \\
$\mathbf{6}$ & $\begin{array}{r}\text { Pensar em si mesmo como aprendizes da ciência e desenvolver uma } \\
\text { identidade como alguém que conhece, usa e às vezes contribui para a ciência }\end{array}$ \\
\hline
\end{tabular}

Fonte: NATIONAL RESEARCH COUNCIL [2009).

ARCH COUNCIL, 2009). Além disso, pesquisas apontam que os espaços não formais, são percebidos como recursos pedagógicos complementares às carências do ambiente escolar e propostas que levem os alunos a conhecerem esses espaços, como por exemplo, centros de ciências nas próprias universidades colaboram para a formação da cultura científica (BIANCONI; CARUSO, 2005). Alguns espaços não formais de Educação têm se constituído como campo para diversas pesquisas, buscando compreender principalmente as relações entre os espaços não formais e a Educação formal no Brasil, no que tange aos conteúdos escolares, uma vez que se criticam os ambientes formais por sua carência e baixa contextualização com o cotidiano. No estudo realizado por Santos e Terán (2017) é possível perceber que a maioria dos trabalhos relacionados aos espaços não formais destacam as áreas de conhecimento centradas no Ensino de Ciência e Matemática, Educação, Ciências Naturais e Artes, assim como, divulgação científica relacionada a ambientes institucionalizados, sendo este último foco deste trabalho.

\section{APONTAMENTOS METODOLÓGICOS}

A presente pesquisa exploratória está situada dentro da abordagem qualitativa a qual se realizou por meio de aplicação de questionário em meio físico com cinco seções (A a E) contemplando perguntas fechadas seguindo uma escala de resposta do tipo Likert de 4 pontos: seção A - Desinteressado/Pouco interessado/Interessado/Muito interessado, seção B - Nada importante/Pouco importante/Muito importante/Extremamente importante, seção C - Nenhuma relação/Pouco relacionado/Muita relação/Extremamente relacionado e seção D e E -
Nunca/Poucas vezes/ Muitas vezes/Sempre. De acordo com Silva Júnior e Costa (2014, p. 5), a pesquisa qualitativa utilizando escala de respostas "consiste em tomar um construto e desenvolver um conjunto de afirmações relacionadas à sua definição, para as quais os respondentes emitirão seu grau de concordância”. Creswell e Clark (2013) mencionam que a pesquisa qualitativa é uma forma de investigação, onde os pesquisadores fazem uma interpretação envolvendo todos os dados para desenvolver um entendimento geral dos mesmos. Ainda, perante o objetivo desta pesquisa que é conhecer e avaliar o interesse dos estudantes em relação à ciência, tecnologia e suas atitudes frente à ciência, Osborne, Simon e Collins (2003), enfatizam o sucesso da utilização dos questionários do tipo Likert, fazendo inventários de interesse por meio de pesquisas qualitativas, assim nos auxiliando na justificativa da escolha da metodologia desta pesquisa, corroborando para a realização da mesma.

O questionário utilizado nesta pesquisa foi estruturado a partir do questionário ROSE, desenvolvido pelos organizadores do projeto The Relevance of Science Education na Noruega (SCHREINER; SJØBERG. 2004), sendo esse adequado ao contexto brasileiro por (Tolentino Neto, 2008). Neste, estão contidas perguntas sobre o nível de interesse em aprender temas relacionados à ciência, suas escolhas em relação à futura profissão e ao seu próprio futuro, sua posição nas questões ambientais, quais assuntos já esteve em contato nas aulas de ciências e quais experiências realizadas fora da escola através de uma lista de 95 itens, organizados nas seções, levando em consideração os temas mais relevantes destacados no questionário ROSE de origem. As perguntas para cada seção estão descritas e, numeradas 
no material suplementar. Os sujeitos-alvo deste estudo são os estudantes que estão completando os útlimos três anos da educação básica, na faixa etária de 14 a 18 anos. Devido ao presente estudo ser realizado em ambiente não formal, houve a necessidade de aplicar o questionário a alunos individualmente, e não junto a turmas de alunos, como realizado no projeto original presente na literatura (SCHREINER; SJØBERG, 2004). As escolas participantes desse estudo são escolas atendidas pelo LENQUI no período de julho de 2018 a maio de 2019. Os estudantes foram sorteados aleatoriamente, pois de acordo com Shank e Brown (2013) este tipo de amostragem permite que os pesquisadores evitem vieses oriundos de seleções sistemáticas, uma vez que estabelece uma média do público alvo. Assim, foram sorteados 76 alunos do $1^{\circ}$ ao $3^{\circ}$ Ano do Ensino Médio, sendo destes 27 representantes do gênero masculino e 49 do gênero feminino, oriundos de 23 escolas da rede pública e particular da cidade de Blumenau - SC.

Os dados gerados foram compilados em gráficos e segregados por gênero para as seções $\mathrm{A}, \mathrm{B}$ e C a fim de apresentar as características da amostra, identificando e comparando o interesse dos estudantes nas questões abordadas com o intuito de diagnosticar o perfil das vocações científico-tecnológicas dos estudantes. As respostas foram observadas em gráficos de barras acumuladas, com o número de indivíduos que assinalaram o item (n), apresentados como marcadores internos. Os eixos dos graficos plotados foram apresentados na forma de porcentagem (y, dependente) e número dos itens dispostos em cada seção ( $\mathrm{x}$, independente). As respostas obtidas na seção denominada $\mathrm{E}$ foram analisadas à luz das vertentes científicas específicas associadas à aprendizagem dos alunos em ambientes informais, preconizadas pelo relatório denominado Learning Science in Informal Environments: People, Places, And Pursuits (NATIONAL RESEARCH COUNCIL, 2009).

\section{RESULTADOS E DISCUSSÃO}

\subsection{A- $O$ que os jovens se interessam em apren- der?}

Nesta seção objetiva-se apresentar os resultados obtidos junto à questão: "Qual é seu nível de interesse em aprender os seguintes assuntos ou temas?" De acordo com Tolentino Neto (2008) e Santos-Gouw (2013), é imprescindível conhecer o que mais (ou menos) interessa aos jovens em relação às ciências, para que mudanças no ensino e nos currrículos escolares (e superiores) possam ser realizadas, de maneira a auxiliar na formação docente, criando novas abordagens e estratégias pedagógicas, materiais didáticos, etc. Ainda, corroborando com essa afirmação, alguns pesquisadores afir- mam que conhecer os temas/assuntos de maior interesse dos jovens pode contribuir para promoção do engajamento destes nas atividades relacionadas com ciências, assim como contribuem para o aumento da motivação e melhoria na aprendizagem (SCHREINER; SJØBERG. 2004). As respostas obtidas na seção A para ambos os gêneros, podem ser observadas na Figura 2, na qual se apresenta um panorama geral dos interesses dos jovens distribuidos em 19 assuntos/temas.

Figura 2: Distribuição das respostas da seção A para o gênero Masculino (gráfico à esquerda) e Femino (gráfico à direita).

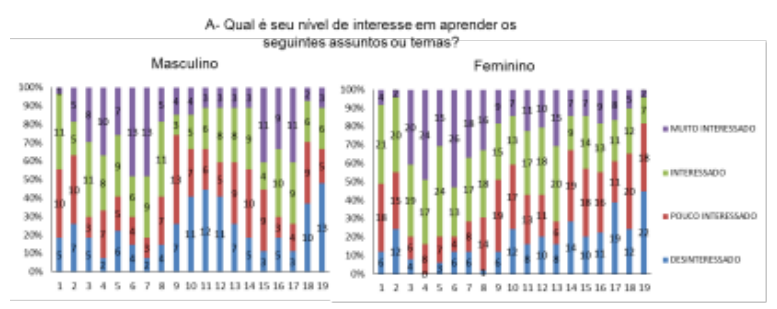

Podemos observar que dos 19 assuntos/temas expostos na Seção A, os que despertam muito interesse, dentre o gênero masculino, estão relacionados às tecnologias. Os temas variam entre Tecnologias na Astronomia $(48,1 \%)$, Tecnologias em geral $(40,7 \%)$ e Programação de computadores $(40,7 \%)$. Destaca-se ainda, que $(40,7 \%)$ demonstram-se interessados nos intens relacionados à química (substâncias e radioatividade). Já dentre o gênero feminino, os itens que muito interessam estão relacionados à vida dentro e fora do planeta, sendo a Astronomia elencada pela maioria das jovens, com $(53,1 \%)$, seguida da Origem e evolução da vida na Terra $(49,0 \%)$, Radioatividade $(40,8 \%)$ e Tecnologias na Astronomia (36,7\%). Além desses, a reprodução e sexualidade foi a mais elencada $(49,0 \%)$ dentro dos itens tidos como de interesse. Cabe ressaltar que, de acordo com Lavonen et al. (2005), alguns fatores podem influenciar nas respostas dos estudantes, como qualidade de ensino, faixa etária e aspectos sociais, sendo assim estes dados, não devem ser considerados como absolutos, pois podem expressar respostas momentâneas. Em seguida, os temas/assuntos que desinteressam dentre o gênero masculino de maneira geral estão ligados à Matemática e Biologia. Nestes, merecem destaque os itens Gráficos e ângulos $(48,1 \%)$, Biodiversidade (44,4\%), Botânica e Educação Alimentar, equiparados com 40,7\% e Materiais recicláveis com $37 \%$ das respostas. Seguindo na mesma tendência, os itens elecandos como desinteressantes pelo gênero feminino são Gráficos e ângulos (44,9\%), Programação de Computadores (38,8\%), Combustíveis (28\%), Materiasi recicláveis, Botânica e cálculos de velocidade e 
transformação de energia com $24,5 \%$ cada um. Notase que há um declínio do interesse de assuntos/temas relacionados à Biologia pelo gênero masculino, como assuntos ligados ao corpo humano, saúde e doenças, porém, vale ressaltar que o tema mais elencado nos itens que englobam a Biologia Humana pelo gênero feminino está relacionado à reprodução e sexualidade. Estes dados coincidem com os apresentados pelo projeto ROSE-Brasil, no que diz respeito aos temas apontados como interessantes relacionados com o "própio corpo, os seus cuidados, como ele funciona, as doenças que o afetam e, é claro, o sexo" (SANTOS-GOUW, 2013 p. 103). Ainda, corroborando com os resultados encontrados nessa seção, pesquisadores apontam que de acordo com os resultados obtidos no projeto ROSEInglaterra, a biologia humana apareceu como sendo a mais pontuada pelo gênero feminino, enquanto que pelo gênero masculino foi a que menos pontuou (JENKINS; NELSON, 2005). De maneira geral, os resultados encontrados nesta seção apontam que o gênero feminino apresenta maior interesse pelos assuntos/temas relacionados à vida humana, conectados com vida dentro e fora do planeta, já os jovens do gênero masculino, têm preferência a temas ligados com a Tecnologia e seus processos na sociedade.

\subsection{B - Temas relevantes na escolha da futura pro- fissão}

Pesquisas têm apontado diminuição nas matrículas em cursos de áreas científicas em decorrência da falta de interesse dos jovens pela ciência escolar (OSBORNE; SIMON; COLLINS, 2003; TRUMPER, 2006). De acordo com Vázquez-Alonso e Manassero-Mas (2009), nos países da Europa, como a Espanha, por exemplo, a globalização da economia e expansão do mercado de trabalho influencia diretamente na diminuição das vocações científicas. Partindo deste contexto, na presente seção apresentam-se os resultados da pergunta que questiona os jovens quanto: "Qual é a importância das seguintes características para a escolha da sua futura profissão?'. A Figura 3 apresenta, de modo geral, a variedade das respostas para a seção B, a qual possui 20 itens, de modo a estabelecer as características da futura profissão com a aproximação do interesse pela ciência.

Dos 20 itens que elecavam os assuntos/temas extremamente importantes para a escolha da futura profissão, tanto para o gênero masculino quanto para o feminino, o item Ter tempo para a minha família foi o mais citado com $59,3 \%$ para o gênero masculino e $69,4 \%$ para o gênero feminino. De acordo com Neresini, Crovato e Saracino (2010), a escolha da futura profissãodos jovens relaciona-se diretamente com o con-
Figura 3: Distribuição das respostas da seção B para o gênero Masculino (gráfico à esquerda) e Feminino (gráfico à direita).

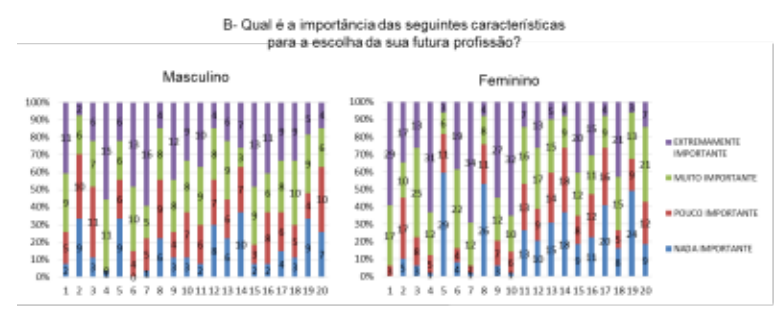

texto social e familiar e nos meios de comunicação, nos quais constrõem seus saberes pessoais junto aos saberes escolares (KOBER, 2008, VÁZQUEZ-ALONSO; MANASSERO-MAS, 2009).

Considera-se, portanto, que para ambos os grupos as respostas podem estar relacionadas ao contexto geral do futuro emprego e não com as características relacionadas ao interesse profissional. Sendo assim, as escolhas que os jovens assinalaram em relação ao seu futuro podem estar relacionadas ao quanto cada uma lhes será significante. $\mathrm{Na}$ amostragem por gênero, as respostas pontuadas como extremamente importantes na escolha da futura profissão pelo grupo masculino são: utilizar meus talentos e capacidades $(55,6 \%)$, ter tempo para meus amigos e trabalhar com pesquisa e novas tecnologias com $48,1 \%$ das respostas para ambas, seguido de ter uma posição de destaque $(44,4 \%)$. Para o grupo feminino, as opções de extrema importância também estão ligadas ao trabalho em equipe $(65,3 \%)$, à utilização dos talentos e capacidades $(63,3 \%)$, trabalhar com pessoas $(59,2 \%)$, além de ter uma posição de destaque $(55,1 \%)$. Ressalta-se aqui, que $51,0 \%$ do grupo feminino elencaram a opção proteger o meio ambiente como muito importante para a escolha da futura profissão, já no grupo masculino apenas $25,9 \%$ considera esse item muito importante. No geral, os resultados por gênero apontam que ambos consideram ter maior importância as profissões que envolvam atividades relacionadas ao contato e valorização das pessoas assim como ter uma posição de destaque.

Diante dessas constatações, podem-se argumentar alguns fatores que afastam os jovens das carreiras científicas, apesar do interesse pela ciência. Polino, Chiappe e Castelfranchi (2011) destacam a qualidade da formação pelo Ensino Médio, quanto aos assuntos e conteúdos, já Güimil (2011), relaciona a falta de interesse dos jovens pelas carreiras científicas com as experiências negativas vividas nas aulas de ciências. Estes resultados encontrados na literatura, possuem uma relação direta com os resultados encontrados no presente estudo, pois reafirmam a falta de conexão dos conteú- 
dos apresentados nas aulas de ciências com a realidade dos alunos no cotidiano.

\subsection{C - Os jovens frente ao seu futuro e do planeta}

A educação científica desempenha papel fundamental na formação dos jovens cidadãos. Por meio do ensino de ciências é possível transmitir conhecimentos científicos, aproximando a natureza da ciência e a prática científica de modo a favorecer as relações entre ciência, tecnologia, sociedade e ambiente (SANTOS-GOUW 2013; CACHAPUZ et al., 2005). No entanto, deve-se oferecer subsídios para que alunos participem de maneira mais consciente no contexto social, para que estes estejam aptos a questionar comportamentos, atitudes e valores (JACOBI, 2005). Como já identificado na literatura, o ensino de ciências vem passando por um grande problema: a falta de motivação e dificuldade no ensinoaprendizagem de conteúdos específicos, principalmente aqueles que envolvam as áreas STEM. As pesquisas que demonstram a visão dos jovens em relação ao futuro e ao futuro do planeta, suas escolhas pessoais e profissionais, são de extrema importância e trazem subsídios para a discussão de conteúdos curriculares que levem ao interesse pela ciência. É neste sentido que esta seção se estrutura em 20 assuntos/temas, de maneira a compreender o que os jovens pensam sobre o futuro: "Qual desses assuntos e temas você considera ter maior relação com o seu futuro e com o futuro do planeta?". Os resultados obtidos e apresentados para a seção C (Figura 47 demonstram que o gênero masculino considera as questões: Ciência e tecnologia digital $(55,6 \%)$ e poluição do ar e da água e uso de internet e aplicativos com $44,4 \%$ cada, extremamente relacionadas ao seu futuro e ao futuro do planeta. Ainda, estes consideram a evolução dos procedimentos médicos $(44,4 \%)$, mobilidade urbana e sustentabilidade $(40,7 \%)$, assim como, as mudanças climáticas globais $(37,0 \%)$, aumento da população (37\%) e qualidade das águas (37\%) como tendo muita relação às questões futuras. $\mathrm{O}$ gênero feminino também demonstrou compreender que os temas: evolução dos procedimentos médicos $(61,2 \%)$, o uso de internet e aplicativos $(53,1 \%)$, proteção à vida animal e abuso de recursos naturais $(51,0 \%)$ estão extremamente relacionados ao futuro do planeta e o seu próprio futuro. Cabe destacar, que estas ainda, indicaram como temas de muita relação: mobilidade urbana (44,9\%), o consumo de energia em excesso $(36,7 \%)$, realidade aumentada, inteligência artificial e direitos humanos com $36,7 \%$ das respostas para cada item.

O conhecimento e a capacitação dos jovens frente às questões ambientais é um importante objetivo da educação (SCHREINER; SJØBERG, 2004). Diversos pes-
Figura 4: Distribuição das respostas da seção C para o gênero Masculino (gráfico à esquerda) e Feminino (gráfico à direita).

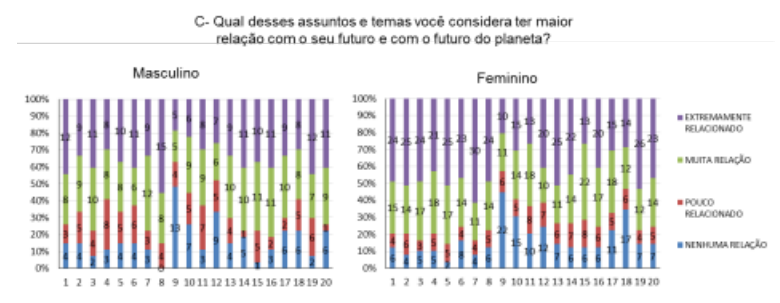

quisadores consideram que há uma relação entre as atitudes ambientais positivas e comportamentos específicos ligados a crenças pessoais, status social, expectativas, hábitos, dentre muitos outros (JENKINS, 2003, JACOBI, 2005). Através dos resultados descritos, podemos perceber que os jovens demonstram que aspectos envolvendo a temática ambiental são extremamente importantes para seu futuro e o futuro do planeta, além de questões relacionadas à medicina. Tuncer et al.(2005) e Taskin (2009) demonstram que as meninas geralmente se preocupam mais e são mais afetivas com relações voltadas à preservação do meio ambiente. Este estudo demonstrou que o gênero feminino demonstra ter mais preocupação a temas ambientais e humanos relacionados com o futuro do que temas que envolvem tecnologia, por exemplo, indo ao encontro aos resultados apresentados por outras pesquisas. Os temas relacionados a: uso de animais em experiências médicas $(48,1 \%)$, uso de agrotóxicos $(33,3 \%)$ e direitos humanos $(29,6 \%)$ foram elencados pelos meninos como sendo os itens que não tem nenhuma relação ou estão pouco relacionados ao seu futuro e do planeta. No grupo das meninas, o tema referente ao uso de animais em experiências médicas $(44,9 \%)$ também foi indicado como sendo o de menos relação, seguido pelos temas: séries e plataformas streaming $(34,7 \%)$ e uso exagerado de produtos de consumo $(30,6 \%)$. Estes resultados se assemelham com os encontrados por Santos-Gouw (2013) ao aplicar o questionário ROSE no Brasil.

\subsection{D - Temas vistos pelos jovens nas aulas de ci- ências}

A preocupação com a melhoria na qualidade do ensino de ciências nas escolas brasileiras é uma questão atual e revela a necessidade de promover atitudes positivas frente à ciência escolar (PECHULA; GONÇALVES; CALDAS, 2013; OSTERMANN; REZENDE, 2015, CARVALHO; GONZAGA; NORONHA, 2017). Reforçando este apontamento, pesquisas têm relacionado o baixo interesse dos jovens pelas carreiras científicas com o baixo desempenho dos estudantes nas aulas 
de ciências (VÁZQUEZ-ALONSO; MANASSEROMAS, 2008; OLIVEIRA; BIZZO, 2018). Neste sentido, a ciência escolar se apresenta como um importante meio de fomento às vocações científico-tecnológicas, portanto, essa seção composta por 20 assuntos/temas pretende identificar quais assuntos são abordados nas aulas de ciências: "Nas suas aulas de Ciências (química, física e biologia) na escola, qual desses assuntos e temas você já teve contato?" Os resultados para ambos os gêneros estão demonstrados na Figura 5

Figura 5: Distribuição das respostas da seção D para ambos os gêneros.

D - Nas suas aulas de Ciênncias (quimica, física e biologia) na escola, qual desses assuntos e temas vocể já teve contato?

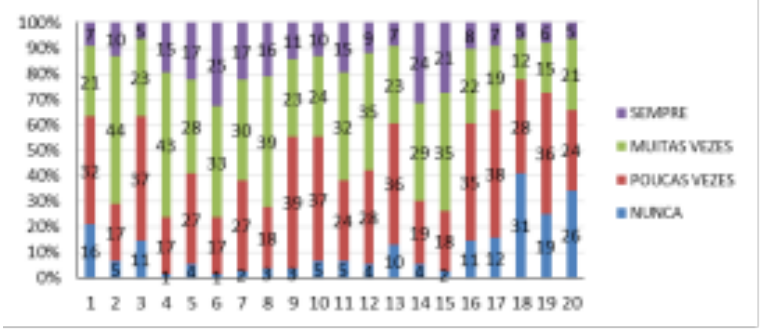

Os resultados desta seção indicam que os assuntos/temas mais vistos pelos jovens nas aulas de ciências (química, física e biologia) de maneira geral são: sistema solar $(44,0 \%)$, o $\operatorname{Ar}(43,0 \%)$, o planeta $(39,0 \%)$, seres vivos $(35,0 \%)$ seguido de ecologia e cadeia alimentar (35,0\%). Já os assuntos/temas nunca ou poucas vezes vistos estão relacionados aos conteúdos de: rochas, minerais e solos (39\%), construção de maquetes e modelos tridimensionais $(38,0 \%)$, a lua e a agricultura com $37 \%$ das respostas para cada item. Como observado anteriormente na seção A (O que os jovens se interessam em aprender?) os assuntos/temas que mais despertam o interesse dos jovens são os relacionados com Tecnologias, Tecnologias na astronomia e a Biologia humana, considerando os interesses de meninos e meninas. Assim sendo, ao nosso entendimento, os materiais didáticos e os currículos de ciências devem considerar um modelo de abordagem metodológica que valorizem estes assuntos e com isso, aumentem o interesse e aprendizado destes conteúdos. Entretanto, temas relacionados a tecnologias, astronomia e biologia humana foram identificados nesta seção como os menos vistos nas aulas de ciências, como por exemplo, o uso de aplicativos e/ou ferramentas de informática $(35 \%)$, o universo $(32,0 \%)$, o uso de protótipos $(31,0 \%)$ e a genética $(19,0 \%)$.

\subsection{E - Os jovens e o contato com espaços não for- mais de aprendizagem científica}

A formação do conhecimento científico está diretamente relaciona à preocupação com a melhora da aprendizagem no ensino de ciências e diversas são as discussões a respeito deste assunto (ZANON; FREITAS, 2007; MORTIMER, 2016). O consumo de informação científica assim como ações que promovam a investigação e responsabilidade social dentro ou fora da escola poderá abrir novos espaços de educação, desencadeando atitudes positivas dos jovens para com a ciência (DE OLIVEIRA; FERREIRA; SANTOS, 2010). Em vista disso, destaca-se a importância de inserção de práticas educativas experimentais realizadas fora do espaço formal de aprendizagem, as quais promovem o desenvolvimento de habilidades de raciocínio científico (BRAUND; REISS, 2006). De acordo com Eshach (2007) o contato dos jovens com atividades fora da escola como visitas a museus, centros e feiras de ciências possuem efeitos intensos sobre as percepções acumuladas ao longo de suas vidas despertando o aprendizado. Assim sendo, essa interação entre o que é aprendido no ambiente escolar e fora dele é importante para a formação de cidadãos cientificamente informados e consientes de suas ações. Para Simpson e Parsons (2009), a grande diferença entre o ensino formal e o não formal é o caráter de livre escolha, sem sequência pré-definida, de ritmo individual e voluntário.

De maneira a facilitar a compreensão e discussão dos resultados em ambientes não formais de aprendizagem optou-se por apresentar na seção E as questões referentes à: "Você já havia visitado um laboratório de ciências como o LENQUI e/ou algum outro espaço não formal de ensino de ciências?" e "Quais dessas experiências ou ações você já realizou fora da escola?", pois ambas tem o objetivo de reconhecer dentre os jovens participantes, quantos consomem informação científica em ambientes não formais e quais são as ações nas experiências realizadas. As respostas dos entrevistados para essas questões encontram-se na Figura 6

Figura 6: Distribuição das respostas sa seção E para ambos os gêneros. Gráfico E1 está relacionado a visitas em ambientes não formais de aprendizagem e o E2 indica quais experiências os jovens tem contato fora do ambiente formal (escola).
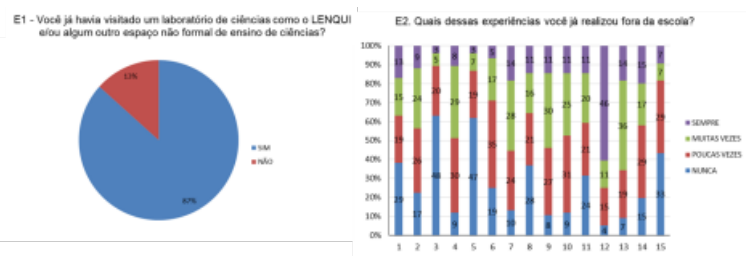
A partir dos dados apresentados, percebe-se que $87 \%$ dos jovens participantes deste estudo estão habituados a frequentar espaços científicos fora da escola. Dentro deste percentual, as experiências ou ações que têm atuado juntamente com a escola na construção de valores em relação às ciências estão relacionadas ao uso de tecnologias $(46,0 \%)$ e plataformas digitais $(36,0 \%)$, realização de experimentos científicos caseiros $(30,0 \%)$, visita a museus e zoológicos $(29,0 \%)$ e utilização de mateirais recicláveis $(25,0 \%)$. Entretanto, observou-se que mesmo a maioria indicando frequentar espaços fora do ambiente escolar que envolva as vocações científico-tecnológicas e áreas STEM percebe-se que as experiências ou ações poucas vezes ou nunca realizadas correspondem à: construção de uma casa na árvore $(48,0 \%)$ e construção de uma composteira $(47,0 \%)$. Além dessas, destacam-se a baixa utilização de kits de ciências $(33,0 \%)$ e utilização de instrumentos de orientação $(29,0 \%)$. Esses dados também se assemelham com outras pesquisas, as quais sugerem que a maior fonte de consumo de informação científica fora do ambiente escolar é na maioria das vezes pelas plataformas digitais e pela televisão. Assim como os dados encontrados neste trabalho, observa-se que pesquisas indicam que há pouco investimento na área científica, pois revelam um baixo percentual de visitação a museu e centros de ciências, bem como zoológicos e feiras de ciências (BRAUND; REISS, 2006, SIMPSON; PARSONS, 2009).

\subsection{F - Análise sob a óptica das vertentes da aprendizagem da ciência}

De acordo com o relatório do National Research Council três são as concepções de aprendizado em ambientes informais: aquelas que se relacionam a aquisição de conhecimentos e competências científicas fundamentais ao longo da vida, como o envolvimento da mídia e o uso da tecnologia (o aprendizado cotidiano), aquelas que ocorrem em ambientes como museus, centros de ciências, jardins botânicos, ou seja, ambientes institucionalizados (ambientes planejados) e também aquelas que ocorrem nas mais variadas situações e ambientes e também estão associadas ao aprendizado de aspectos culturais, a valores morais, éticos, religiosos e sociais (programas fora da escola e programas para adultos) (2009, p. 28 tradução nossa). Sendo assim, neste trabalho procuramos identificar as vertentes da aprendizagem informal, relacionadas às concepções de aprendizado em ambientes planejados. Os dados analisados nessa seção referem-se aos apresentados na seção denominada E - Os jovens e o contato com espaços não formais de aprendizagem científica. As vertentes (strands) já demonstradas na Tabela 1, além de serem um instrumento importante para detectar o aprendizado informal, revelam uma dimensão do aprendizado científico que vai além dos sistemas de ensino formais. Portanto, a partir dos resultados apresentados, compreendeu-se que o envolvimento com a investigação científica em ambientes planejados, bem como a aquisição de linguagens, ferramentas e normas científicas, como proposto na vertente 5 , estão presentes no cotidiano dos jovens entrevistados, na medida em que demonstraram participar de atividades relacionadas às areas da ciência.

\section{CONSIDERAÇÕES FINAIS}

Pelos dados aqui apresentados e por meio de outras pesquisas, percebe-se que os jovens possuem grande interesse pela ciência, mantendo a tendência no sentido da preocupação com a vida humana, assim como sobre problemas e desafios ambientais relacionados ao futuro do planeta. Assim sendo, as reformulações nos currículos podem estar na contramão da opinião dos estudantes quanto aos temas relevantes e interessantes para as aulas de ciências, podendo assim manifestar no não engajamento destes pelas escolhas das futuras profissões relacionadas à ciência e tecnologia. Essa barreira pode ser quebrada, impulsionando as estratégias de ensino que abordem os temas apontados pela opnião dos jovens frente aos interesses pelas ciências, levando em consideração os conhecimentos conceituais e sua relevância no ensino de Física, Química e Biologia e sua adequação às competências e habilidades específicas apontados pela BNCC. Diante disso, as futuras pesquisas e discussões a respeito das reformulações nos currículos escolares, ao nosso entendimento, devem levar em consideração não só as opiniões de especialistas, como dos pesquisadores, professores e estudantes, de maneira a conectar os conteúdos específicos do currículo com as necessidades desses para o mundo contemporâneo. O sucesso das iniciativas referentes à aprendizagem científica nos faz acreditar que o ensino em ambientes não formais, também reconhecidos como informais, possuem um enorme potencial a ser explorado, principalmente no que diz respeito à sua capacidade de motivar o aluno para o aprendizado das áreas STEM os quais valorizam a promoção das vocações científicotecnológicas. Os resultados encontrados nos projetos realizados pelo LENQUI têm demonstrado que, iniciativas que visam aproximar o aluno às ciências do cotidiano, não somente aquelas que destinam-se a assimilar os conteúdos conceituais obrigatórios dos currículos escolares, vão de encontro a um ensino de qualidade promovendo uma aprendizagem verdadeiramente sig- 
nificativa.

\section{REFERÊNCIAS}

ALONSO, Á. V.; MAS, M. A. M. La relevancia de la educación científica: actitudes y valores de los estudiantes relacionados con la ciencia y la tecnología. Enseñanza de las ciencias: revista de investigación y experiencias didácticas, v. 27, n. 1, p. 33-48, 2009.

ARRUDA, S. d. M.; PASSOS, M. M.; PIZA, C. A. d. M.; FELIX, R. A. B. O aprendizado científico no cotidiano. Ciência \& Educação (Bauru), SciELO Brasil, v. 19, n. 2, p. 481-498, 2013.

BARAM-TSABARI, A.; YARDEN, A. Characterizing children's spontaneous interests in science and technology. International Journal of Science Education, Taylor \& Francis, v. 27, n. 7, p. 803-826, 2005.

BIANCONI, M. L.; CARUSO, F. Educação não-formal. Ciência e cultura, Sociedade Brasileira para o Progresso da Ciência, v. 57, n. 4, p. 20, 2005.

BRASIL. Base Nacional Comum Curricular. Brasília, 2018.

BRAUND, M.; REISS, M. Towards a more authentic science curriculum: The contribution of out-of-school learning. International journal of science education, Taylor \& Francis, v. 28, n. 12, p. 1373-1388, 2006.

CACHAPUZ, A.; GIL-PEREZ, D.; CARVALHO, A. d.; PRAIA, J.; VILCHES, A. A necessária renovação do ensino das ciências. 1. ed. São Paulo: Cortez, 2005.

CARVALHO, M.; GONZAGA, A.; NORONHA, E. Divulgação científica: dimensões e tendências, tendências no ensino de ciências e matemática. Revista Aretél Revista Amazônica de Ensino de Ciências, v. 4, n. 7, p. 99-114, 2017.

ESHACH, H. Bridging in-school and out-of-school learning: Formal, non-formal, and informal education. Journal of science education and technology, Springer, v. 16, n. 2, p. 171-190, 2007.

EUROPEAN COMMISSION. Europe needs more scientists! Report by the High level Group on Increasing Human Resources for Science and Technology in Europe. Luxembourg: Office for Official Publications of the European Communities, 2004. 187 p.
FOUREZ, G. Crise no ensino de ciências?

Investigações em ensino de ciências, v. 8, n. 2, p. 109-123, 2016.

GÜIMIL, U. El efecto de la estructura del sistema educativo en la elección de las carreras científicas en montevideo. In: ORGANIZACIÓN DE LOS ESTADOS IBEROAMERICANOS PARA LA EDUCACION, LA CIENCIA Y LA CULTURA. Buenos Aires: OEI, 2011.p. 183-204.

JACOBI, P. R. Educação ambiental: o desafio da construção de um pensamento crítico, complexo e reflexivo. Educação e pesquisa, SciELO Brasil, v. 31, n. 2 , p. $233-250,2005$

JACOBUCCI, D. F. C. Contribuições dos espaços não-formais de educação para a formação da cultura científica. Revista em extensão, v. 7, n. 1, p. 55-66, 2008.

JENKINS, E. W. Environmental education and the public understanding of science. Frontiers in Ecology and the Environment, Wiley Online Library, v. 1, n. 8, p. $437-443,2003$.

JENKINS, E. W.; NELSON, N. Important but not for me: Students' attitudes towards secondary school science in england. Research in Science \& Technological Education, Taylor \& Francis, v. 23, n. 1, p. 41-57, 2005.

JR, W. E. F.; FRANCISCO, W. Proteínas: Hidrólise, precipitação e um tema para o ensino de química. Química Nova na Escola, v. 24, n. 1, p. 12-16, 2006.

KAROLCZAK, M. E. Recursos humanos capacitados nas áreas de ciências, tecnologia, engenharia, matemática e afins: uma análise na ótica da teoria do capital humano no contexto brasileiro. 147 p. Tese (Doutorado em Administração) - Universidade do Vale do Rio dos Sinos, Brasil, 2017.

KOBER, C. M. Tempo de decidir: produção da escolha profissional entre jovens do ensino médio. 319 p. Tese (Doutorado em educação) — Universidade estadual de Campinas, Campinas, 2008.

LAVONEN, J.; JUUTI, K.; UITTO, A.; MEISALO, V.; BYMAN, R. Attractiveness of science education in the finnish comprehensive school. In: Research findings on young people's perceptions of technology and science educatio. Finland: Technology Industries of Finland, 2005. p. 5-30. ISBN 951-817-886-0. 
MORTIMER, E. F. Construtivismo, mudança conceitual e ensino de ciências: para onde vamos? Investigações em ensino de ciências, v. 1, n. 1, p. 20-39, 2016.

\section{NATIONAL RESEARCH COUNCIL. Learning} science in informal environments: people, places, and pursuits. Washington: National Academies Press, 2009.

NERESINI, F.; CROVATO, S.; SARACINO, B. Scienza e nuove generazioni. I risultati dell'indagine internazionale ROSE. Vicenza: Edizione Observa, 2010. 189 p.

OLIVEIRA, G.; BIZZO, N. Ciência escolar e ciência fora da escola: opiniões e interesses de jovens brasileiros. Revista de Educação Pública, v. 28, n. 67, p. 195-217, 2018.

OSBORNE, J.; SIMON, S.; COLLINS, S. Attitudes towards science: A review of the literature and its implications. International journal of science education, Taylor \& Francis, v. 25, n. 9, p. 1049-1079, 2003.

OSTERMANN, F.; REZENDE, F. Os mestrados profissionais em ensino das ciências da natureza no brasil. Ciência \& Educação (Bauru), SciELO Brasil, v. 21, n. 3, p. I-III, 2015.

PECHULA, M. R.; GONÇALVES, E. M.; CALDAS, G. Divulgação científica: discurso, mídia e educação. controvérsias e perspectivas. Redes. com: revista de estudios para el desarrollo social de la Comunicación, Universidad de Sevilla, v. 1, n. 7, p. 201-212, 2013.

PINAFO, J. O que os jovens têm a dizer sobre ciência e tecnologia? Opiniões, interesses e atitudes de estudantes em dois países: Brasil e Itália. 463 p. Tese (Doutorado em Educação) - Universidade de São Paulo, São Paulo, 2016.

SANTOS-GOUW, A. M. As opiniões, interesses e atitudes dos jovens brasileiros frente à ciência: uma avaliação em âmbito nacional. 242 p. Tese (Doutorado em Educação) — Universidade de São Paulo, São Paulo, 2013.

SANTOS, S.; TERÁN, A. O uso da expressão espaços não formais no ensino de ciências. Revista Aretél Revista Amazônica de Ensino de Ciências, v. 6, n. 11, p. 01-15, 2017.
SASSERON, L. H. Alfabetização científica, ensino por investigação e argumentação: relações entre ciências da natureza e escola. Ensaio Pesquisa em Educação em Ciências (Belo Horizonte), SciELO Brasil, v. 17, n. 1, p. 49-67, 2015.

SCHREINER, C.; SJØBERG, S. Sowing the seeds of ROSE: background, rationale, questionnaire development and data collection for ROSE (The Relevance of Science Education): a comparative study of students' views of science and science education. 2004. Acta didactica http://urn. nb. no/URN: NBN: no-14449.

SCHWAHN, M. C. A.; OIAGEN, E. R. O uso do laboratório de ensino de química como ferramenta: investigando as concepções de licenciandos em química sobre o predizer, observar, explicar (poe). Acta Scientiae, v. 10, n. 2, p. 151-169, 2008.

SEDANO, L.; CARVALHO, A. M. P. de. Ensino de ciências por investigação: oportunidades de interação social e sua importância para a construção da autonomia moral. Alexandria: Revista de Educação em Ciência e Tecnologia, v. 10, n. 1, p. 199-220, 2017.

Silva Júnior, S. D. d.; COSTA, F. J. Mensuração e escalas de verificação: uma análise comparativa das escalas de likert e phrase completion. PMKT-Revista Brasileira de Pesquisas de Marketing, Opinião e Mídia, v. 15, n. 1-16, p. 61, 2014.

SIMPSON, J. S.; PARSONS, E. C. African american perspectives and informal science educational experiences. Science Education, Wiley Online Library, v. 93, n. 2, p. 293-321, 2009.

TASKIN, O. The environmental attitudes of turkish senior high school students in the context of postmaterialism and the new environmental paradigm. International Journal of Science Education, Taylor \& Francis, v. 31, n. 4, p. 481-502, 2009.

Tolentino Neto, L. C. B. d. Os interesses e posturas de jovens alunos frente às ciências: resultados do Projeto ROSE aplicado no Brasil. 172 p. Tese (Doutorado em educação) - Universidade de São Paulo, São Paulo,, 2008.

TôZO, C. d. O. O papel da divulgação científica na formação das crianças: a experiência da estação ciência. 270 p. Dissertação (Mestrado em Processo Comunicacionais) - Universidade Metodista de São Paulo, São Bernardo do Campo, 2005. 
TRUMPER, R. Factors affecting junior high school students' interest in physics. Journal of science Education and Technology, Springer, v. 15, n. 1, p. $47-58,2006$.

TUNCER, G.; ERTEPINAR, H.; TEKKAYA, C.; SUNGUR, S. Environmental attitudes of young people in turkey: Effects of school type and gender. Environmental education research, Taylor \& Francis, v. 11, n. 2, p. 215-233, 2005.

VÁZQUEZ-ALONSO, Á.; MANASSERO-MAS,

M. A. El declive de las actitudes hacia la ciencia de los estudiantes: un indicador inquietante para la educación científica. Revista Eureka sobre Enseñanza y Divulgación de las ciencias, Universidad de Cádiz, v. 5, n. 3, p. 274-292, 2008.

La relevancia de la educación científica: actitudes y valores de los estudiantes relacionados con la ciencia y la tecnología. Enseñanza de las ciencias: revista de investigación y experiencias didácticas, v. 1, n. 1, p. 33-48, 2009.

VIEIRA, V.; BIANCONI, M. L.; DIAS, M. Espaços não-formais de ensino e o currículo de ciências. Ciência e Cultura, Sociedade Brasileira para o Progresso da Ciência, v. 57, n. 4, p. 21-23, 2005.

WOMER, R. A Importância das aulas práticas para o ensino e a aprendizagem de química e biologia. 35 p. Dissertação (Trabalho de Conclusão de Curso (Especialização)) - Universidade Tecnológica Federal do Paraná, Medianeira, 2014.

ZANON, D. A. V.; FREITAS, D. D. A aula de ciências nas séries iniciais do ensino fundamental: ações que favorecem a sua aprendizagem. Ciências \& Cognição, v. 10, n. 1, p. 93-103, 2007. 